\title{
Resolução de conflitos: sentimentos e justificativas de adolescentes
}

\section{Conflict solving: Adolescents' feelings and justifications}

Vanessa Fagionatto Vicentin é doutora em Psicologia Escolar e do Desenvolvimento Humano pela Universidade de São Paulo; professora da Universidade de Franca; professora do curso de especialização latu sensu "As relações interpessoais na escola e a construção da autonomia moral".

\section{Contato: vanessafvv@bol.com.br}

Maria Isabel da Silva Leme é livre-docente em pesquisa pela Universidade de São Paulo (2006) e professora titular da mesma universidade.

\section{Contato: belleme@usp.br}

\section{RESUMO}

Estudiosos da área apontam três principais estilos de resolução de conflito: agressivo, submisso e assertivo. 0 objetivo do presente estudo foi verificar possíveis relações entre estratégia de solução de conflito, expressão de sentimentos e justificativa indicadas por adolescentes. Participaram da investigação 84 estudantes com idades entre 12 e 16 anos. 0 instrumento utilizado foi uma adaptação do questionário derivado da escala Children's Action Tendency Scale (DELUTY, 1981). As respostas predominantes relacionadas aos conflitos foram submissão e coerção. Grande parte dos participantes não se pronunciou com relação aos sentimentos provocados pelas situações descritas pelo questionário. A avaliação que visou comparar a expressão de sentimentos com as justificativas das respostas de enfrentamento dos participantes nas situações de conflito mostrou várias associações significativas por

1. Artigo elaborado a partir da tese de doutorado de V.F. Vicentin, intitulado Condições de vida $e$ estilos de resolução de conflitos entre adolescentes (223 páginas) apresentado em 2009 ao Programa de Pós-Graduação em Psicologia da Universidade de São Paulo. Agradecemos o apoio financeiro da CNPQ pela realização desta pesquisa (processo $\mathrm{n}^{\circ}$ 140551/2005). 
meio do teste exato de Fisher. Com relação à expressão de sentimentos, muitos conflitos apresentaram associações positivamente significativas entre as respostas agressivas e ausência de manifestação sobre o afeto despertado pela situação.

Palavras-chave: Conflitos. Sentimentos. Adolescentes.

\begin{abstract}
Scholars point to three main strategies of conflict resolution: aggressive, submissive and assertive. The aim of this study was to investigate possible relationships between expression of feelings and strategies employed for resolving conflict displayed by 84 students, aged between 12 and 16 years. The instrument used was an adaptation of the Children's Action Tendency Scale (DELUTY, 1981). The predominant responses found to conflict were submission and coercion. Most participants did not express the feelings caused by the situations described by the questionnaire, followed by those who expressed negative feelings or poorly defined. The evaluation aimed to compare the expression of feelings with the justification of the coping responses of the participants in conflict situations showed several significant associations through the Fisher exact test. Regarding the expression of feelings, significant positive associations between aggressive responses and lack of demonstration of affection aroused by the situation were found.

Keywords: Conflict. Feelings. Adolescents.
\end{abstract}

Diversos estudiosos consideram que os conflitos interpessoais podem caracterizar-se como uma oportunidade para 0 desenvolvimento pessoal e interpessoal (SHANTZ; HARTUP, 1992; ABRAMOVAY, 2005; VINHA; TOGNETTA, 2009), em virtude da complexidade envolvida nesse tipo de situação e da forma como é conduzido.

No cotidiano, os dados sobre formas injustas e desequilibradas de resolver conflitos são inquietantes. Waiselfisz (2008) afirma que o índice de morte por arma de fogo no Brasil ocupa lugar de destaque no contexto internacional, já que ocorrem 19,3 óbitos em 100 mil habitantes. As dificuldades para resolver desacordos de forma pacífica levando ações violentas já podem ser encontradas entre os indivíduos mais jovens como os escolares. Ilustrando essa afirmação, um estudo coordenado por Abramovay (2005) com alunos do Ensino 
Fundamental (a partir da $6^{a}$ série) e do Ensino Médio de cinco capitais do Brasil (Belém, Salvador, São Paulo, Porto Alegre e Distrito Federal) evidenciou que $20 \%$ dos alunos afirmam que já bateram em alguém na escola, $14 \%$ dos estudantes dizem já terem sido ameaçados e $34,8 \%$ afirmam já terem visto algum tipo de arma na escola. Dessa forma, configura-se como tarefa urgente para os pesquisadores estudar os aspectos relacionados aos conflitos interpessoais, a fim de contribuir para o planejamento de ações que possam favorecer a construção de formas mais evoluídas de resolver os desacordos interpessoais, em especial, entre as novas gerações.

Deluty (1979) e Leme (2004) distinguem três principais estratégias utilizadas pelas pessoas para a resolução de conflitos interpessoais: agressiva, submissa e assertiva. A estratégia agressiva caracterizase pelo enfrentamento da situação de conflito interpessoal apelando para formas de coerção, como violência ou desrespeito ao direito, sentimento e opinião alheia. A estratégia submissa caracterizase pelo não enfrentamento de uma situação por meio de fuga ou esquiva, frequentemente pela consideração dos direitos, ideias e sentimentos dos outros em detrimento dos próprios. Por fim, a estratégia assertiva também envolve enfrentamento da situação de conflito, porém sem qualquer tipo de coerção. Caracteriza-se por comportamentos explícitos de defesa dos próprios direitos, mas levando em consideração os direitos, sentimentos, ideias e opiniões alheias. 0 termo estilo de resolução de conflito é aqui utilizado para indicar a reação comportamental predominante de uma pessoa diante de desacordos interpessoais, o que não significa que outras estratégias não possam ser utilizadas.

Vale observar que diante de um mesmo fato as pessoas reagem de formas diferentes. É possível que essas mesmas pessoas reajam de forma ainda distinta em outros momentos de suas vidas, em outros ambientes ou com outras pessoas. Leme (2004) lembra que os conflitos interpessoais são situações que mobilizam conjuntamente recursos cognitivos e afetivos, o que é fundamental para a escolha de diferentes estratégias de resolução diante de um desentendimento interpessoal.

Diante de um conflito interpessoal, a pessoa confrontada com os desejos e as ideias dos outros necessita, para encontrar uma boa solução, descentrar-se de sua perspectiva, a fim de poder considerar a do outro. A resolução de conflito de maneira satisfatória requer um trabalho cognitivo em função desse processo de descentração, o que implica operações de reciprocidade e síntese entre contrários. Além disso, para uma solução equilibrada é preciso um pensamento 
progressivamente operatório, que antecipe e reconstrua as ações no plano mental (TOGNETTA, 2009). Nesse caso, parece ser necessário, em princípio, o desenvolvimento cognitivo para que ocorra a descentração e a consequente evolução na capacidade de coordenar diferentes pontos de vista.

Quanto aos recursos afetivos mobilizados pelo indivíduo durante um conflito interpessoal, Sastre e Moreno (2002) lembram que durante décadas a psicologia estudou separadamente os processos cognitivos e afetivos. Entretanto, essa visão vem sendo questionada por trabalhos da psicologia e neurologia, que demonstram que cognição e afeto participam conjuntamente nas ações das pessoas. Damásio (1996) foi um dos pioneiros a confirmar a estreita relação entre cognição e afeto, apontando que os sistemas cerebrais responsáveis pelos respectivos processamentos estão interligados, não só entre si, mas ainda com os que regulam reações corporais. Para o autor, as emoções são um conjunto de mudanças que se produzem no estado corporal, induzidas por terminais de neurônios situados em diferentes órgãos do corpo, que são controlados por determinadas áreas do sistema cerebral, que respondem ao conteúdo dos pensamentos do indivíduo, enquanto o sentimento é o processo de viver essa emoção.

Damásio (1996) realizou estudos em pacientes com lesões cerebrais que dentre outros aspectos reconheciam meios eficazes de resolver conflitos sociais, mas que eram incapazes de aplicá-los na vida cotidiana. Seus estudos constataram que as lesões haviam comprometido a associação entre as áreas de processamento cognitivo e afetivo, evidenciando a importância da integridade cognitiva para a seleção de estratégias favoráveis à resolução.

A psicologia cognitiva também tem muito a contribuir para a compreensão da relação entre o pensamento e os sentimentos, processos internos indissociáveis das ações humanas e, consequentemente, dos conflitos interpessoais. Isso porque considera que, desde muito cedo, o indivíduo é dotado da capacidade de atribuir significados aos estímulos. Bruner (1997, p.120) endossa essa última afirmação e completa: "Com alguma dificuldade maior, mas ainda facilmente, a criança também 'aprende como significar' - como se referir ao mundo com sentido". Nessa concepção teórica, os seres humanos exibem uma tendência natural para representar internamente os significados da existência concreta externa (ABREU; ROSO, 2003). Além disso, o indivíduo ao se deparar com o mundo buscará classificar os eventos em categorias como certo ou errado, bom ou mau, verdadeiro ou falso. Esse processo será responsável 
pela construção de crenças e valores que serão, nessa perspectiva, a base de tomada de decisões.

Detalhando mais esses processos de atribuição de significado, o processamento de informação social ocorre de acordo com as seguintes operações: codificação dos dados sociais, representação dos mesmos, busca por respostas possíveis, seleção da resposta e ação propriamente dita. A etapa de codificação trata as informações, tanto internas quanto externas, que seriam representadas e interpretadas, o que nas etapas seguintes, levaria à seleção do objetivo, decisão sobre a resposta e atuação. Segundo esse modelo, as emoções, no caso, como informações internas, são parte integrante do modelo. Já na década de 1980, Dodge elaborou um modelo de processamento das informações sociais por indivíduos agressivos (DODGE; COIE, 1987) que teve grande repercussão nas pesquisas subsequentes. Assim, foi identificado que algumas falhas no processamento poderiam explicar o comportamento agressivo, tanto em função de uma codificação tendenciosa da situação, como de uma maior limitação na capacidade de gerar e decidir sobre possíveis respostas para as situações de impasse, de acordo com Vasconcellos e colaboradores (2006), que realizaram revisão da literatura sobre o processamento de informações sociais de crianças e adolescentes agressivos.

Especificando mais o processamento do afeto, Schultz, Izard e Bear (2004) identificaram alguns tipos de processamento de emoção que se relacionam à agressão: acurácia ou viés na atribuição de emoção, e presença ou ausência de empatia. No que diz respeito ao processo de atribuição, verificaram que crianças que se consideram mais felizes e que são vistas como tal atribuem emoções ao outro mais corretamente, sendo também mais empáticas. Já crianças mais propensas a sentir raiva tem maior probabilidade de errar, por atribuir essa mesma emoção ao outro, assim como crianças mais medrosas tendem mais a atribuir medo ao outro. Ao que tudo indica, crianças agressivas processam a informação diferentemente desde a pré-escola, pois já tendem a atribuir hostilidade ou más intenções aos outros, e também são menos empáticas do que crianças não agressivas. Como crianças agressivas experienciam raiva mais frequentemente do que outras crianças, e são mais rápidas em se enraivecer diante de situações como levar um esbarrão, interpretado como acidental por crianças mais pacíficas, é provável que sejam menos procuradas para interagir do que as últimas, e assim tem menos oportunidade de aprender sobre as intenções alheias. 0 viés no processo de atribuição das crianças agressivas também pode ser atribuído ao menor conhecimento adquirido nas interações sociais se tiverem menos habilidade verbal, em termos da extensão do 
vocabulário. A dificuldade na expressão verbal pode prejudicar a compreensão do que é dito em uma interação social, fazendo com que a criança não só tenha mais dificuldade em entender o outro como ainda de expressar-se. Assim, não ganha experiência, o que impacta subsequentemente a acurácia na comunicação da emoção, própria e a do outro. A frustração resultante de interações mal sucedidas pode contribuir ainda para o crescimento da hostilidade em relação ao outro e aumentar a probabilidade de agressão futura (FINE; IZARD; TRENTACOSTA, 2006).

Observa-se assim que como os sentimentos, segundo o modelo cognitivo, são derivados dos padrões de pensamentos e crenças, o conflito que uma pessoa vive não determina em si a forma como se sentirá, mas sim os juízos de valor a ele associados, que se relacionam a uma resposta emocional específica. Poderíamos então afirmar que os sentimentos são uma expressão do funcionamento do mundo interno do indivíduo. Eles são decorrentes do significado que a pessoa atribui a uma situação, lembrando que esses significados nem sempre são conscientes e que são decorrentes de sua história de vida (ABREU; ROSO, 2003).

A cultura também desempenha um papel importante na expressão dos sentimentos e emoções, em virtude do tipo de relação com o grupo valorizado e incutido na socialização. Em culturas coletivistas, em que a relação de interdependência entre as pessoas é enfatizada pelo alto valor que tem para a manutenção do grupo, as emoções negativas como raiva são vistas como perigosas e a habilidade em escondê-las é valorizada. Já nas individualistas, em que a autonomia individual é mais valorizada que a harmonia e a manutenção do grupo, a manifestação de emoções, mesmo que negativas, é muito mais aceita (VIKAN; DIAS; ROAZZI, 2009).

A psicologia moral aponta que para uma solução justa de conflitos interpessoais é preciso não só colocar-se no lugar do outro, mas também eleger essa opção. La Taille (2006) afirma que para que um indivíduo possa agir bem é preciso que ele "pense bem" e "queira agir bem", indicando a necessidade de recursos cognitivos e afetivos para uma solução equilibrada de conflitos interpessoais. É preciso a vontade de considerar o outro e a si mesmo antes de tomar decisões.

Os sentimentos atuam como pistas da estrutura e funcionamento do mundo interno do indivíduo, tanto para a psicologia cognitiva quanto para a psicologia moral, ainda que com diferentes perspectivas sobre o seu papel na ação. Dessa forma, vários autores sustentam que o trabalho com os sentimentos é fundamental para o desenvolvimento satisfatório do indivíduo (TOGNETTA, 2003; SASTRE; 
MORENO, 2002). Falar sobre sentimentos é colaborar para que o indivíduo compreenda que as dimensões internas estão associadas de alguma forma às suas ações. Tognetta (2003) afirma que é necessário o autoconhecimento a fim de que se conquiste o autodomínio. Favorecer a conscientização dessa dimensão afetiva pode levar o indivíduo a buscar a compreensão de formas alternativas de expressão emocional. No mesmo sentido, Abreu e Roso (2003, p. 27) afirmam que "o processamento consciente das emoções, enquanto sentimentos, proporciona a ampliação dos mecanismos de resolução de problemas, isto é, sentir as emoções amplia o alcance delas, facilitando novas formas de ação, mais talhadas para a ocasião". Verifica-se assim que, para os autores, reconhecer os sentimentos é um passo para o desenvolvimento de um mundo interno equilibrado e para escolhas mais justas nos conflitos interpessoais.

Tendo em vista as considerações acima sobre a importância dos sentimentos para o funcionamento psicológico mais adaptado em relação ao outro, foi realizado o estudo descrito a seguir, que teve como objetivo analisar a relação entre a manifestação dos sentimentos e o estilo de resolução de conflito de adolescentes. Nossa hipótese inicial era que os adolescentes que reconhecem os próprios sentimentos teriam melhores condições de reconhecer os do próximo e, portanto, de resolver o conflito de forma negociada ou conciliatória, o que exige a coordenação de direitos, sentimentos e ideias de todos.

\section{Método}

\subsection{Participantes}

Participaram do estudo 84 adolescentes, na faixa etária de 12 a 16 anos, estudantes de uma escola pública da região de Campinas.

\subsection{Instrumento}

Para analisar as tendências de resolução de conflitos, foi utilizado o questionário aberto derivado da escala Children's Action Tendency Scale (DELUTY, 1981). Trata-se de instrumento que descreve 10 conflitos interpessoais fictícios envolvendo pais, amigos ou colegas que provocam situações de frustração, perdas, ameaças e outras.

Em cada conflito apresentado é perguntado ao participante o que faria se estivesse naquela situação. Para aprofundar a compreensão do processo, atendendo ao objetivo de avaliar o papel 
dos sentimentos nas ações do indivíduo, logo antes da pergunta sobre a reação foi acrescentada a questão: "o que você sentiria se estivesse nesta situação?". Por último, solicitou-se que o adolescente respondesse a questão "por quê?" em todas as situações de conflito interpessoal. A justificativa do indivíduo sobre suas ações foi incluída a fim de colaborar com a caracterização da estratégia de resolução de conflito utilizada, já que apenas a ação pode ser insuficiente para essa finalidade e pode ser motivada por diversas justificativas.

\subsection{Procedimentos}

Após contato com a direção da escola e participação de uma reunião pedagógica em que foi explicado o objetivo do projeto aos docentes, foi realizado um estudo-piloto em função das adaptações realizadas no instrumento descrito acima. A coleta de dados definitiva foi realizada com a $7^{\mathrm{a}}$ e a $8^{\mathrm{a}}$ série do Ensino Fundamental e o $1^{\circ}$ ano do Ensino Médio após o agendamento com os docentes.

\subsection{Análise dos dados}

As respostas sobre a resolução de conflito foram categorizadas em agressivas, submissas, assertivas ou mistas (combinando simultaneamente elementos de submissão e assertividade, submissão e agressividade ou agressividade e assertividade), de acordo com a ação do indivíduo e sua justificativa. Foi realizada uma avaliação da categorização feita por um juiz psicólogo, com o qual se obteve concordância de $95 \%$.

Os sentimentos expressos pelos participantes foram categorizados de acordo com os critérios de tonalidade afetiva explicitada, positiva ou negativa, grau de definição, pouco definido ou definido, e ainda, posicionamento em relação à ação ou juízo alheio.

Utilizou-se seis categorias de expressão de sentimentos. A categoria 1 envolve sentimentos positivos ou de indiferença (ex: normal, nada, não ligaria), enquanto a categoria 2 envolve sentimentos negativos pouco definido pelos participantes (ex: mal, nada bem, ruim). Os sentimentos negativos que envolvem a não aceitação em relação à ação alheia, como raiva, bravo e injustiçado, foram agrupados na categoria 3. Já os sentimentos negativos que envolvem a inferiorizarão em relação a ação alheia, como humilhado, magoado e excluído, foram agrupados na categoria 4 . A categoria 5 envolve sentimentos que decorrem da aceitação do juízo alheio ou do autojuízo negativo, como vergonha e culpa, e a categoria 6 diz respeito aos que não se pronunciam sobre os sentimentos. 
Essa categorização dos sentimentos também foi avaliada por meio da comparação com a realizada por um juiz, especialista nessa área, tendo se obtido um índice de $100 \%$ de concordância entre ambos.

\section{Resultados}

Os resultados relativos às respostas dos participantes deste estudo nas 10 situações de conflito propostas pelo instrumento evidenciaram que $39,29 \%$ do grupo de adolescentes apresentaram respostas categorizadas como submissas, seguidos por $28,57 \%$ dos participantes que indicaram respostas agressivas. Dos participantes que responderam ao material, 19,05\% não apresentaram predominância de respostas e apenas 5,95\% dos participantes tinham uma predominância de respostas assertivas. Os participantes com respostas categorizadas como mistas formam a minoria, já que $4,76 \%$ dos adolescentes tiveram respostas predominantemente submisso-agressivas e $2,38 \%$ respostas agressivo-assertivas. Não houve participantes que tendessem predominantemente para a categoria submisso-assertiva.

Não foi encontrada associação significativa entre as categorias de sentimentos e as tendências de solução de conflitos. Contudo, foi constatado que ao mesmo tempo dois participantes não expressaram sentimentos em todas as situações de conflitos. Um análise por meio do teste exato de Fisher comparando os grupos quanto a expressão ou não de sentimentos indicou a existência de diferenças significativas entre os dois grupos no que diz respeito à seleção da estratégia.

No conflito que descrevia uma situação de atribuição de responsabilidade ao participante pelos seus pais por um problema causado por um amigo, os dados revelaram uma diferença significativa $(p=0,004)$; sendo que os participantes que não expressam seus sentimentos apresentam mais respostas agressivas $(70,59 \%)$ e submissas $(66,67 \%)$; enquanto os participantes que expressaram sentimento apresentaram mais respostas assertivas $(64,71 \%)$ ou mistas $(63,33 \%)$. Além disso, todos os participantes que não indicaram uma estratégia para solucionar o conflito expressaram sentimentos despertados pela situação (tabela 1). 
Tabela 1: Comparação entre os participantes que expressam ou não os sentimentos com a proporção de respostas em cada estilo de resolução nas situações de conflito.

\begin{tabular}{|c|c|c|c|c|c|c|c|}
\hline Conflito & $\begin{array}{l}\text { Expressa } \\
\text { Sentimento }\end{array}$ & Agressiva & Misto & Assertiva & $\begin{array}{l}\text { Não indica } \\
\text { estratégia }\end{array}$ & Submissa & $\begin{array}{c}\text { Teste Exato } \\
\text { de Fisher }\end{array}$ \\
\hline \multirow{3}{*}{1} & Não & $45,45 \%$ & $20 \%$ & $0 \%$ & $0 \%$ & $18,18 \%$ & \\
\hline & Sim & $54,55 \%$ & $80 \%$ & $100 \%$ & $100 \%$ & $81,82 \%$ & $P=0,089$ \\
\hline & Não & $70,59 \%$ & $36,67 \%$ & $35,29 \%$ & $0 \%$ & $66,67 \%$ & \\
\hline \multirow[t]{2}{*}{2} & Sim & $29,41 \%$ & $63,33 \%$ & $64,71 \%$ & $100 \%$ & $33,33 \%$ & $P=0,004$ \\
\hline & Não & $44,19 \%$ & $53,33 \%$ & $36,36 \%$ & $33,33 \%$ & $33,33 \%$ & \\
\hline \multirow[t]{2}{*}{3} & Sim & $55,81 \%$ & $46,67 \%$ & $63,64 \%$ & $66,67 \%$ & $66,33 \%$ & $P=0,855$ \\
\hline & Não & $51,35 \%$ & $40,74 \%$ & $35,71 \%$ & $0 \%$ & $50 \%$ & \\
\hline \multirow[t]{2}{*}{4} & Sim & $48,65 \%$ & $59,26 \%$ & $64,29 \%$ & $100 \%$ & $50 \%$ & $P=0,663$ \\
\hline & Não & $51,85 \%$ & $55,17 \%$ & $50 \%$ & $16,67 \%$ & $58,33 \%$ & \\
\hline \multirow[t]{2}{*}{5} & Sim & $48,15 \%$ & $44,83 \%$ & $50 \%$ & $83,33 \%$ & $41,67 \%$ & $P=0,546$ \\
\hline & Não & $55,56 \%$ & $38,89 \%$ & $66,67 \%$ & $16,67 \%$ & $26,67 \%$ & \\
\hline \multirow[t]{2}{*}{6} & Sim & $44,44 \%$ & $61,11 \%$ & $33,33 \%$ & $83,33 \%$ & $73,33 \%$ & $P=0,153$ \\
\hline & Não & $69,23 \%$ & $64,71 \%$ & $66,67 \%$ & $0 \%$ & $36,11 \%$ & \\
\hline \multirow[t]{2}{*}{7} & Sim & $30,77 \%$ & $35,29 \%$ & $33,33 \%$ & $100 \%$ & $63,89 \%$ & $P=0,008$ \\
\hline & Não & $66,67 \%$ & $60 \%$ & - & $0 \%$ & $34,29 \%$ & \\
\hline \multirow[t]{2}{*}{8} & Sim & $33,33 \%$ & $40 \%$ & - & $100 \%$ & $65,71 \%$ & $P=0,006$ \\
\hline & Não & $60 \%$ & $47,37 \%$ & $57,14 \%$ & $20 \%$ & $75 \%$ & \\
\hline \multirow[t]{2}{*}{9} & Sim & $40 \%$ & $52,63 \%$ & $42,86 \%$ & $80 \%$ & $25 \%$ & $P=0,022$ \\
\hline & Não & $40 \%$ & $30 \%$ & $46,15 \%$ & $0 \%$ & $30 \%$ & \\
\hline 10 & Sim & $60 \%$ & $70 \%$ & $53,85 \%$ & $100 \%$ & $70 \%$ & $P=0,024$ \\
\hline
\end{tabular}

Em um conflito descrito como causado pelos pais, que desejam que o participante cumpra o horário de dormir no meio de um programa de TV também foi verificada uma diferença significativa $(p=0,008)$. Os dados que se destacam é a relação entre expressão ou não de sentimento e estratégia usada, pois todos os participantes que não indicaram estratégia de enfrentamento e os que usaram estratégias submissas $(63,89 \%)$ expressaram seus sentimentos, enquanto os que apresentam respostas agressivas $(69,23 \%)$, mistas $(64,71 \%)$ ou assertivas $(66,67 \%)$ tenderam a não expressá-los. Observa-se que os participantes que indicam estratégias agressivas novamente mostram tendência a não se expressar quanto aos sentimentos. 
Semelhante a esse último resultado, o conflito que envolvia ter recusado um pedido de partilha de um chocolate por um amigo resultou em uma associação significativa $(p=0,006)$ entre ausência de manifestação e estratégia. Como no conflito anterior, os participantes que forneceram respostas agressivas $(66,67 \%)$ tenderam a não expressar os sentimentos.

Também no conflito causado pela crítica de um colega sobre a inteligência do participante foi encontrada uma diferença de $p=0,022$, entre os adolescentes que não expressaram sentimentos e os que expressaram, pois os primeiros apresentaram mais respostas submissas $(75 \%)$, agressivas $(60 \%)$, assertivas (57,14\%). Já os adolescentes que expressaram o que sentiriam nessa situação não responderam o que fariam $(80 \%)$ ou apresentaram respostas mistas $(52,63 \%)$. Mais uma vez, verifica-se que a resposta agressiva encontra-se associada à ausência de expressão de sentimentos, e a manifestação dos mesmos à ausência de resposta.

Esse resultado se repete no conflito que envolve a perda de um prêmio para um colega por um ponto, no qual foi verificada uma diferença significante de $p=0,024$. Novamente todos os adolescentes que não responderam o que fariam nessa situação se expressaram quanto aos sentimentos. Também expressaram sentimento os que apresentaram mais respostas submissas $(70 \%)$ e mistas $(70 \%)$. Já os que não expressaram sentimentos deram mais respostas assertivas $(46,15 \%)$ ou agressivas $(40 \%)$. Observou-se que, em muitas situações de conflito estudadas, os participantes que fornecem respostas categorizadas como agressivas estão associados a não expressão de seus sentimentos.

Em suma, os resultados relativos à expressão de sentimentos dos participantes e os estilos de resolução de conflito indicam algumas associações que se repetem em várias situações de conflito. Em metade dos conflitos apresentados, as respostas agressivas estão significantemente mais associadas $(p<0,05)$ à ausência de expressão de sentimentos quando comparadas às outras estratégias de resolução dos conflitos.

Durante a análise dos resultados, também foi observado que alguns participantes do estudo não justificaram suas ações, assim como ocorreu com a expressão de sentimentos. Diferenças significativas também foram verificadas através do teste exato de Fisher com relação às tendências de resolução de conflito e presença ou ausência de justificativa para a ação $(p<0,05)$. No conflito causado por um amigo que devolve danificado o livro preferido do participante, foi verificada através do teste exato de Fisher uma 
diferença significante $(p=0,029)$, entre os adolescentes que mais justificam ações e os que não justificam. Os primeiros apresentaram mais respostas assertivas $(78,57 \%)$, mistas $(62,96 \%)$ ou não responderam como agiriam (100\%), enquanto os que não justificam suas ações $(62,16 \%)$ deram respostas categorizadas como agressivas (tabela 2).

Um resultado semelhante ao descrito acima apareceu no conflito causado por uma bolada na cabeça dada por uma criança menor $(p<0,001)$. Novamente os participantes que fornecem respostas agressivas não justificam suas ações (70,37\%), assim como os que deram respostas assertivas ( $80 \%)$. Da mesma forma que no conflito anterior, os participantes que não respondem como agiriam nessa situação fornecem justificativas $(66,67 \%)$, assim como os que deram respostas mistas $(79,31 \%)$ e submissas $(58,33 \%)$.

No conflito causado pelos pais que esperam ver cumprido o horário de dormir, também surgiu uma diferença significante $(p=0,026)$, pois novamente os adolescentes cujas respostas foram categorizadas como agressivas não justificaram suas ações (76,92\%), assim como os que deram respostas categorizadas como assertivas (75\%) e mistas $(70,59 \%)$. Os participantes que não responderam o que fariam nesse conflito novamente apresentaram mais justificativas $(66,67 \%)$, assim como os participantes que forneceram estratégias submissas $(61,11 \%)$.

Na situação que envolvia ter um pedido de partilha de um chocolate negado por um amigo foram encontrados resultados que corroboram de forma significativa $(p=0,009)$ alguns resultados dos conflitos já destacados. Novamente os participantes que apontaram respostas agressivas não justificaram suas ações (83,33\%), assim como aqueles que deram respostas mistas (64\%). Já entre os que justificaram, verifica-se que $54,29 \%$ deram respostas submissas ou não responderam o que fariam $(83,33 \%)$ 
Tabela 2: Comparação entre os participantes que justificam ou não sua resposta com a proporção de respostas em cada estilo de resolução nas situações de conflito.

\begin{tabular}{|c|c|c|c|c|c|c|c|}
\hline Conflito & $\begin{array}{c}\text { Expressa } \\
\text { Sentimento }\end{array}$ & Agressiva & Misto & Assertiva & $\begin{array}{l}\text { Não indica } \\
\text { estratégia }\end{array}$ & Submissa & $\begin{array}{l}\text { Teste Exato } \\
\text { de Fisher }\end{array}$ \\
\hline \multirow{3}{*}{1} & Não & $45,45 \%$ & $20 \%$ & $60 \%$ & $25 \%$ & $30,30 \%$ & \multirow{3}{*}{$P=0,285$} \\
\hline & Sim & $54,55 \%$ & $80 \%$ & $40 \%$ & $75 \%$ & $75 \%$ & \\
\hline & Não & $47,06 \%$ & $56,67 \%$ & $41,18 \%$ & $0 \%$ & $50 \%$ & \\
\hline \multirow[t]{2}{*}{2} & Sim & $52,94 \%$ & $43,33 \%$ & $58,82 \%$ & $100 \%$ & $50 \%$ & \multirow[t]{2}{*}{$P=0,057$} \\
\hline & Não & $53,49 \%$ & $46,67 \%$ & $45,45 \%$ & $66,67 \%$ & $50 \%$ & \\
\hline \multirow[t]{2}{*}{3} & Sim & $46,51 \%$ & $53,33 \%$ & $54,55 \%$ & $33,33 \%$ & $50 \%$ & \multirow[t]{2}{*}{$P=0,979$} \\
\hline & Não & $62,16 \%$ & $37,04 \%$ & $21,43 \%$ & $0 \%$ & $50 \%$ & \\
\hline \multirow[t]{2}{*}{4} & Sim & $37,84 \%$ & $62,96 \%$ & $78,57 \%$ & $100 \%$ & $50 \%$ & \multirow[t]{2}{*}{$P=0,029$} \\
\hline & Não & $70,37 \%$ & $20,69 \%$ & $80 \%$ & $33,33 \%$ & $41,67 \%$ & \\
\hline \multirow[t]{2}{*}{5} & Sim & $79,31 \%$ & $79,31 \%$ & $20 \%$ & $66,67 \%$ & $58,33 \%$ & \multirow[t]{2}{*}{$P<0,001$} \\
\hline & Não & $55,56 \%$ & $27,78 \%$ & $83,33 \%$ & $50 \%$ & $35,56 \%$ & \\
\hline \multirow[t]{2}{*}{6} & Sim & $44,44 \%$ & $72,22 \%$ & $16,67 \%$ & $50 \%$ & $64,44 \%$ & \multirow[t]{2}{*}{$P=0,119$} \\
\hline & Não & $76,92 \%$ & $70,59 \%$ & $75 \%$ & $33,33 \%$ & $38,89 \%$ & \\
\hline \multirow[t]{2}{*}{7} & Sim & $23,08 \%$ & $29,41 \%$ & $25 \%$ & $66,67 \%$ & $61,11 \%$ & \multirow[t]{2}{*}{$P=0,026$} \\
\hline & Não & $83,33 \%$ & $64 \%$ & - & $16,76 \%$ & $45,71 \%$ & \\
\hline \multirow[t]{2}{*}{8} & Sim & $16,67 \%$ & $36 \%$ & - & $83,33 \%$ & $54,29 \%$ & \multirow[t]{2}{*}{$P=0,009$} \\
\hline & Não & $80 \%$ & $31,58 \%$ & $64,29 \%$ & $20 \%$ & $36,11 \%$ & \\
\hline \multirow[t]{2}{*}{9} & Sim & $20 \%$ & $68,42 \%$ & $35,71 \%$ & $80 \%$ & $63,89 \%$ & \multirow[t]{2}{*}{$P=0,064$} \\
\hline & Não & $60 \%$ & $26,67 \%$ & $38,46 \%$ & $18,75 \%$ & $30 \%$ & \\
\hline 10 & Sim & $40 \%$ & $73,33 \%$ & $61,54 \%$ & $81,25 \%$ & $70 \%$ & $P=0453$ \\
\hline
\end{tabular}

Esses resultados mostram que em quase metade dos conflitos, os participantes que apresentaram respostas categorizadas como agressivas tenderam a não justificar suas ações, enquanto os que se justificaram tenderam a não responder o que fariam. Convém lembrar que, da mesma forma verificada quanto à expressão de sentimentos, em que as respostas agressivas estavam mais associadas à ausência de manifestação de sentimento, as respostas agressivas foram as que mais se associaram à ausência de justificativa. Observa-se ainda que, da mesma forma encontrada entre os que manifestaram sentimentos, os que justificaram suas ações tenderam a não responder o que fariam. Em vista desses últimos resultados, é possível que os adolescentes que não responderam qual seria a 
estratégia de resolução de conflito escolhida, e ao mesmo tempo manifestaram sentimentos e justificativas, estariam justificando os seus sentimentos e não suas ações. Em outros termos, é possível ainda que $o$ aspecto mais saliente ou relevante tenha sido o sentimento e a justificativa nesses casos e não a ação.

\section{Discussão}

Um dado de muita relevância evidenciado pela análise estatística refere-se à associação significativa entre uso de estratégias agressivas e ausência de expressão de sentimentos em vários conflitos. Qual o motivo para essa associação? Os resultados de algumas pesquisas podem sugerir possíveis respostas. Motivadas pelos dados sobre o crescimento da violência mundial, Sastre e Moreno (2003) realizaram uma pesquisa sobre a experiência de injustiça entre universitários de terceiro e quarto ano. A análise dos textos dos alunos revelou resultados semelhantes aos do presente estudo. Ao descrever o modelo de pessoa que age injustamente, "a quase totalidade dos estudantes descreveu com detalhes o comportamento visível dos agressores e fez pouca referência aos sentimentos e pensamentos subjacentes aos comportamentos externos descritos tão minuciosamente" (SATRE; MORENO, 2003, p. 136). Os estudantes descreveram os personagens que agem injustamente como pessoas que privilegiam seus próprios interesses, que não pensam na dor do outro, o que é atribuído por Sastre e Moreno (2003) à primazia dada pelos estudantes às ações do indivíduo, e depois, a descrição dos pensamentos e sentimentos. Como exemplo, destacamos diversas respostas de participantes que foram categorizadas como resoluções de conflito agressivas e não expressam sentimentos ou justificativa: "batia nele e iria embora" (conflito que envolve ser humilhado por colega por errar em um jogo), "eu xingava e se a pessoa rateasse batia nela" (conflito que envolve ser empurrado fora da fila da cantina por um colega), "faço ele pagar outro" (conflito que envolve ter o livro preferido devolvido danificado por um amigo), "mando engolir o jogo e procuro algo melhor para fazer" (conflito que envolve a recusa de colegas a pedido para participar de um jogo), "falava para ele que tomara que dê uma dor de barriga" (conflito que envolve ter a recusa de um pedido de partilha de um chocolate), "falava que ele é muito metido" (conflito que envolve a crítica de um colega pela inteligência do participante) e "falava que perdi porque quis" (conflito que envolve perda de premio para um colega por um ponto em um jogo).Fica claro que as respostas envolvem o foco em resolver o próprio mal-estar de forma imediata e não evidenciam consciência de sentimentos, 
motivos ou formas alternativas de ação. Como já apontamos em outro momento, endossamos a posição de La Taille (2006) de que os investimentos afetivos precisam ser objeto de reconhecimento para que o indivíduo tenha condições de realizar escolhas mais equilibradas.

A fim de evidenciar que os sentimentos estão interligados à tomada de decisão dos indivíduos, Tognetta (2006) realizou estudo com 150 adolescentes com idades entre 12 e 15 anos com o objetivo de avaliar a possível correspondência entre os julgamentos morais e as representações que o indivíduo tem de si mesmo. Para tal, a autora investigou se o sentimento de admiração estava ligado a conteúdos éticos ou conteúdos individuais. Os adolescentes do estudo foram submetidos a uma entrevista aberta sobre as ações admiráveis nos outros e admiráveis em si, e a outra, também aberta, com base em histórias que evidenciam situações de humilhação que poderiam permitir a disposição para a generosidade. Tanto o grupo cujas ações admiráveis estavam ligadas a ações éticas (ações que denotam preocupação também com o outro), como o grupo em que a admiração estava ligada a ações individuais, julgaram da mesma forma, pela necessidade de ações generosas. Entretanto uma diferença importante se destacou com relação aos sentimentos; os grupos cujas representações de si estavam vinculadas a conteúdos éticos apresentaram maior sensibilidade com relação aos sentimentos dos personagens envolvidos nas situações descritas. Transcrevendo uma conclusão da autora (TOGNETTA, 2006, p. 277):

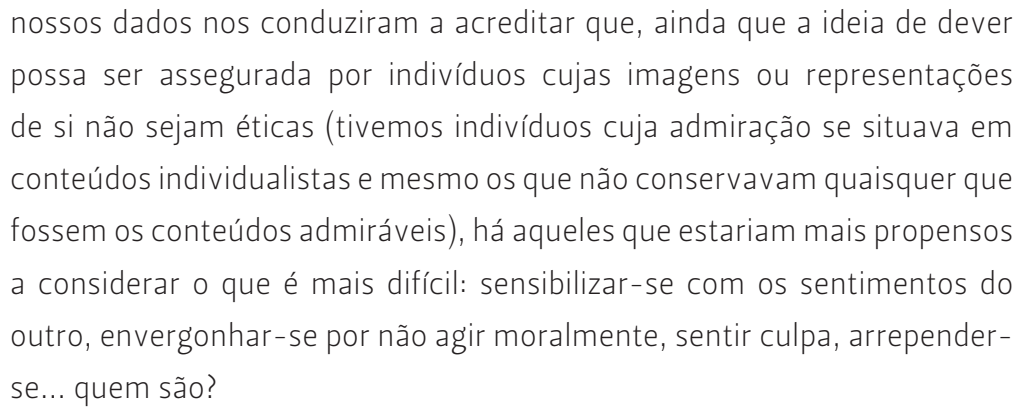

Diante de tais considerações é possível afirmar que o fato de o participante apresentar dificuldade em reconhecer os próprios sentimentos e, consequentemente, os do próximo colabora para que ele indique reações agressivas em situações de desacordos interpessoais. Além disso, a emergência em resolver o próprio mal-estar e satisfazer os próprios desejos prejudica a avaliação dos próprios aspectos afetivos e, consequentemente, dos do outro, além da consideração de formas alternativas para a resolução do problema, o que implica ações imediatistas e agressivas. Provavelmente é isso que está causando a ausência de manifestação. 
Os objetivos de controle de pessoas e objetos estão mais associados à agressão, enquanto os de manutenção da relação, aos conciliatórios (BALLIF-SPANVILLE; CLAYTON; HENDRIX, 2003). As evidencias fornecidas pela psicologia cognitiva de dificuldades de aquisição de conhecimento social pelas crianças agressivas em função de suas reações que afastam os pares (SCHULTZ; IZARD; BEAR, 2004; FINE; IZARD; TRENTACOSTA, 2006) também podem explicar os resultados encontrados no presente estudo.

A análise que relaciona as justificativas do participante e as estratégias de resolução de conflito adotadas pode ser sustentada pelas discussões já realizadas até o momento, já que os resultados apontam na mesma direção. A maioria dos participantes que não justificaram suas ações tenderam a escolher estratégias de resolução de conflito agressivas. Já destacamos anteriormente que para uma boa solução de conflito é necessário pensar por reciprocidade e buscar conciliar os contrários (SASTRE; MORENO, 2002). Para tanto, é preciso reconhecer os próprios sentimentos, desejos e direitos, assim como as do outro.

Quanto aos participantes que escolhem estratégias agressivas de resolução de conflito, os estudos apresentados neste tópico sugerem o desconhecimento de seus valores (LA TAILLE, 2006) e também de seus sentimentos (TOGNETTA, 2003), assim como a pouca sensibilidade para motivos do outro (TOGNETTA, 2006), o que dificulta a percepção dos motivos para as próprias ações. Não se pode descartar a hipótese de que em virtude da busca de satisfação imediata das próprias necessidades, a maioria deles não se expressa quanto às justificativas. Isso parece se confirmar na análise dos motivos dos participantes cujas respostas foram categorizadas como agressivas: "Sairia xingando... porque eu não tenho sangue de barata", "xingava meus pais... porque a culpa não foi minha", "empurraria ele para fora da fila... porque ele me empurrou primeiro", "pegava a bola e jogava na cabeça dele... porque ele tem que parar quando os outros estão passando", "chamaria ele de chato... porque ele não dividiu comigo e eu estava com vontade" e "argumentaria em tom de deboche...porque ele está querendo ser mais". Fica claro que a reação agressiva parece necessária diante da ação do outro em vista da necessidade de resolver o próprio mal-estar.

Em suma, os resultados que apontam uma maior associação entre a expressão de sentimentos e a estratégia de solução assertiva e a ausência de expressão de sentimentos e a estratégia agressiva fortalecem a nossa hipótese inicial sobre a probabilidade de aqueles adolescentes que reconhecem os próprios sentimentos terem 
melhores condições de reconhecer os do próximo e, portanto, resolver o conflito de forma não violenta. Quanto às justificativas dos participantes sobre suas ações, os dados também evidenciaram uma associação maior entre ausência de justificativas e tendências de resolução de conflito agressiva. Vários estudos relacionam a estratégia de resolução de conflito agressiva às reações impulsivas e ao objetivo de satisfação própria imediato. Esses dados nos permitem concluir que o participante que adota reações agressivas tende a reagir antes de considerar todos os elementos de um conflito ou, ainda, a escolher satisfazer apenas os próprios desejos.

\section{Considerações Finais}

A análise sobre as estratégias de solução de conflito e a expressão dos sentimentos dos participantes, assim como as justificativas de suas ações, apontou resultados que contribuíram para as conclusões. Os dados indicam que os participantes que não expressam sentimentos usam mais resoluções de conflito agressivas.

Ao considerar as justificativas dos participantes do estudo, observa-se que aqueles que adotam estratégias agressivas também apresentam menos justificativas para suas ações, o que fortalece a concepção de que os adolescentes que apontam ações agressivas reagem mais impulsivamente e com finalidade de satisfazer os próprios objetivos.

Pode-se concluir que, sem oportunidades de aprendizagem que levem a melhores maneiras de solução de conflito, a maioria das pessoas entende, como único recurso, deixar de defender os próprios direitos, ou fazer valer os seus direitos custe o que custar. É um esquema de domínio-submissão já apontado por Fernandez (2005) ou luta ou fuga indicado por Deluty (1981). Diante desse panorama, encontramos situações cada vez mais frequentes de agressividade e violência escolar, casos de agressividade furtiva (com roubos, furtos, ameaças) e relações desarmoniosas que se prolongam na vida adulta, no ambiente de trabalho, conjugal, com filhos e amigos.

Sustentamos que o ambiente escolar pode ajudar a encontrar caminhos para a busca de uma sociedade justa. A instituição educacional se depara diariamente com situações de conflito entre os pares. 0 educador enfrenta cotidianamente situações que envolvem o pensar sobre a ação mais adequada para que um aluno que agrediu outro perceba as consequências de sua atitude, e o outro, que se submeteu, reflita sobre o motivo que permitiu a agressão. As 
ações dos educadores diante de conflitos com os alunos e entre os alunos podem contribuir para que estes adotem ações agressivas, submissas ou assertivas nas situações de desacordos interpessoais. Ações programadas sugeridas por Sastre e Moreno (2002), Tognetta (2003, 2009) e Vicentin (2009) sugerem atividades periódicas na escola para que os alunos possam falar sobre sentimentos e discutir formas alternativas de solução de conflitos, a fim de não se tornarem analfabetos emocionais.

\section{REFERÊNCIAS}

ABRAMOVAY, M. Cotidiano das escolas: entre violências. Brasília, UNESCO, Observatório da violência, Ministério da Educação, 2005.

ABREU, C. N.; ROSO, M. (Orgs.). Psicoterapiascognitivas e construtivistas: novas fronteiras de prática clínica. Porto Alegre: Artmed, 2003.

BALLIFF-SPANVILL, B.; CLAYTON,C.J.; HENDRIX, S.B. Gender, types of conflict, and individual differences in the use of violent and peaceful strategies among children who have or have not witnessed interparental violence. American Journal of Orthopsychiatry, v. 73,n. 2, p.141-153, 2003.

BRUNER, J. Realidades mentais, mundos possíveis. Tradução M. S. Domingues. Porto Alegre: Artes Médicas, 1997.

DAMÁSIO, A. R. O erro de Descartes: emoção, razão e o cérebro humano. Tradução portuguesa Vicente D. e Segurado G. São Paulo: Companhia de Letras, 1996.

DELUTY, R. H. Alternative thinking ability of aggressive, assertive, and submissive children. Cognitive Therapy and Research, n. 5, p. 309-312, 1979.

DELUTY, R.H. Children's evaluation of aggressive, assertive, and submissive responses. Journal of Clinical Psychology, $v$. 12, n. 2, p.124-129, 1981.

DODGE, K.A.; COIE J.D. Social-Information-Processing Factors in Reactive and Proactive Aggression in Children's Peer 
Groups. Journal of Personality and Social Psychology. v.53, n.6, 1146-1158, 1987.

FERNÁNDEZ, I. Prevenção da violência e solução de conflitos: o clima escolar como fator de qualidade. tradução de FulvioLubisco, São Paulo: Madras, 2005.

FINE, S. E.; IZARD, C. E.; TRENTACOSTA C. J. Emotion situation knowledge in elementary school: models of longitudinal growth and preschool correlates. Social Development. $v$ 15, n.4, 730-751, 2006.

LA TAILLE Y. Moral e Ética: dimensões intelectuais e afetivas. Porto Alegre: Artmed, 2006.

LEME, M. I. S. Resolução de conflitos interpessoais: interação entre cognição e afetividade na cultura. Psicologia Reflexão e Crítica, Porto Alegre, v. 17, n. 3, 2004.

SASTRE, G. V.; MORENO, M. O significado afetivo e cognitivo das ações. In: ARANTES, V. A. (Org.). Afetividade na escola. São Paulo: Summus, 2003.

SASTRE, G. V.; MORENO, M. Resolução de conflitos e aprendizagem emocional: gênero e transversalidade. Tradução Ana Venite Fuzato. São Paulo: Moderna, 2002.

SCHULTZ, D.; IZARD, C. E.; BEAR, G. Children's emotion processing: relations to emotionality and aggression. Development and psychopatology, v. 16, p.371-387, 2004.

SHANTZ, C. U.; HARTUP, W.W. Conflict in child and adolescent development. New York: Cambridge University Press, 1992.

TOGNETTA, L. R. P. A construção da solidariedade e a educação do sentimento na escola. Campinas, SP: Mercado de Letras, São Paulo: Fapesp. 2003.

TOGNETTA, L. R. P. Sentimentos e virtudes: um estudo sobre a generosidade ligado as representações de si. 2006. 320 p. Tese de doutorado. Instituto de Psicologia. Universidade de São Paulo, 2006.

TOGNETTA, L. R. P. Perspectiva ética e generosidade. Campinas: Mercado de Letras/FAPESP, 2009. 
VASCONCELLOS, S. J. L.; PICON, P.; PROCHNOW, L. P.; GAUER, G. J. C. O processamento das informações sociais em crianças e adolescentes agressivos. Estudos de Psicologia Natal, 11, 3, p. $275-279,2006$.

VICENTIN, V.F. E quando chega a adolescência... Uma reflexão sobre o papel do educador na resolução de conflitos entre adolescentes. Campinas, SP: Mercado de Letras, 2009.

VIKAN, A; DIAS, M. G. B. B.; ROAZZI, A. Rating emotion communication: display and concealment as effects of culture, gender, emotion type and relationship. Revista Interamericana de Psicologia, 43, 1, p. 77-83, 2009.

VINHA, T. P.; TOGNETTA, L.R.T. Construindo a autonomia moral na escola: os conflitos interpessoais e a aprendizagem de valores. Revista Diálogo Educacional, v.9, n.28, p.525-540. 2009.

WAISELFISZ, J. Mapa da violência dos municípios Brasileiros. Rede de Informações Tecnológicas Latino-Americana, RITLA, Instituto Sangari, Ministério da Saúde. Ministério da Justiça, 2008.

Recebido em: 11/02/2014

Aprovado em: 04/04/2014 